\title{
First Blindness Cases of Horses Infected with Setaria Digitata (Nematoda: Filarioidea) in the Republic of Korea
}

\author{
Jihun Shin ${ }^{1, \dagger}$ Kyu-Sung Ahn', Guk-Hyun Suh², Ha-Jung Kim², Hak-Sub Jeong ${ }^{3}$, Byung-Su Kim4, Eunsang Choi \\ Sung-Shik Shin ${ }^{1, *}$
}

${ }^{1}$ Department of Parasitology and ${ }^{2}$ Clinical Medicine, College of Veterinary Medicine, Chonnam National University, Gwangju 61186, Korea; ${ }^{3}$ Bongsun Veterinary Clinic, Gwangju 61671, Korea; ${ }^{4}$ YeongGwang Veterinary Clinic, Jeollanam-do 57043, Korea; ${ }^{5}$ Smile Animal Clinic, Busan 46745, Korea

\begin{abstract}
Ocular setariases of cattle were reported but those of equine hosts have never been reported in the Republic of Korea (Korea). We found motile worms in the aqueous humor of 15 horses (Equus spp.) from 12 localities in southern parts of Korea between January 2004 and November 2017. After the affected animals were properly restrained under sedation and local anesthesia, $10 \mathrm{ml}$ disposable syringe with a 16-gauge needle was inserted into the anterior chamber of the affected eye to successfully remove the parasites. The male worm that was found in 7 of the cases showed a pair of lateral appendages near the posterior terminal end of the body. The papillar arrangement was 3 pairs of precloacal, a pair of adcloacal, and 3 pairs of postcloacal papillae, plus a central papilla just in front of the cloaca. The female worms found in the eyes of 8 horses were characterized by the tapering posterior terminal end of the body with a smooth knob. Worms were all identified as Setaria digitata (von Linstow, 1906) by the morphologic characteristics using light and electron microscopic observations. This is the first blindness cases of 15 horses infected with S. digitata (Nematoda: Filarioidea) in Korea.
\end{abstract}

Key words: Setaria digitata, ocular setariasis, horse blindness, corneal opacification, Korea

Adult worms of the genus Setaria Viborg, 1795 (Nematoda: Filarioidea) are transmitted by mosquitoes and are commonly found free within the peritoneal cavity of ungulates [1]. In Korea, Rhee et al. [2] reported 2 species of Setaria, S. digitata and $S$. marshalli, found in the abdominal cavity of cattle by the application of scanning electron microscopy. Larvae of Setaria spp. often invade other organs such as the brain and spinal cord of sheep, goat, horse, and cattle causing cerebrospinal injuries $[3,4]$, or lumbar paralysis [5-7]. Worms have also been found in the urinary bladder [8] and the epicardium or pericardium $[9,10]$. Larvae of Setaria spp. frequently migrate into the eye of cattle and horses where they cause blindness [11-13].

Since horses are mainly raised for riding and sports activities, cloudiness of the cornea, decreased vision, or blindness due to ocular setariasis can be detrimental and even fatal.

\footnotetext{
• Received 13 November 2017, revised 27 November 2017, accepted 11 December 2017. *Corresponding author (sungshik@jnu.ac.kr)

† Current address for Jihun Shin: Department of Parasitology, Seoul National University College of Medicine, Seoul 03080, Korea.

(C) 2017, Korean Society for Parasitology and Tropical Medicine

This is an Open Access article distributed under the terms of the Creative Commons Attribution Non-Commercial License (http://creativecommons.org/licenses/by-nc/4.0) which permits unrestricted non-commercial use, distribution, and reproduction in any medium, provided the original work is properly cited.
}

Equine ocular setariasis caused by several species of Setaria, including S. equina, S. marshalli and S. digitate, has been reported in the eyes of donkeys and horses [12,14,15]. Among 242 horses with ocular disorders in India, 138 cases (57.0\%) were diagnosed as ocular setariasis during 10 years from 2002 to 2011 [16].

We previously reported the first case of ocular setariasis of cattle in the Republic of Korea (Korea) in 2002 in which a 5-month-old female native Korean calf and a 2-year-old female Holstein cow were found to be unilaterally blind, and single $S$. digitata worm was isolated from the aqueous humor of each of the affected eye [13]. Since then, additional cases of ocular setariasis have not been reported until present in Korea. We report herein 15 cases of equine ocular setariasis caused by S. digitata (von Linstow, 1906), as identified by both light and scanning electron microscopies.

In January 2004, a 5-year-old male Jeju pony (Equus caballus) was found to have a left eye opaque at a local horse farm in Gyeongsan-si, Gyeongsangbuk-do, Korea. In contrast to the healthy and non-affected right eye, the cornea of the left eye was leukomatous to the extent that the affected eye did not respond to any movement on the left side of the face. An al- 
most identical case was developed in a horse farm in Miryangsi, Gyeongsangnam-do, Korea, at the same period. The right eye of a 6-year-old Thoroughbred gelding was found to be opaque, and a white worm was observed rapidly swimming within the anterior chamber (Fig. 1). Additional 13 cases of equine ocular setariasis were identified from October 2012 to November 2017 (Table 1).

Worms were removed from the affected eye of each horse as previously described by Shin et al. [13] by the needle puncture aspiration (NPA) technique. Briefly, after the animal was properly restrained under sedation and local anesthesia, $10 \mathrm{ml}$ disposable syringe with a 16-gauge needle was inserted into the

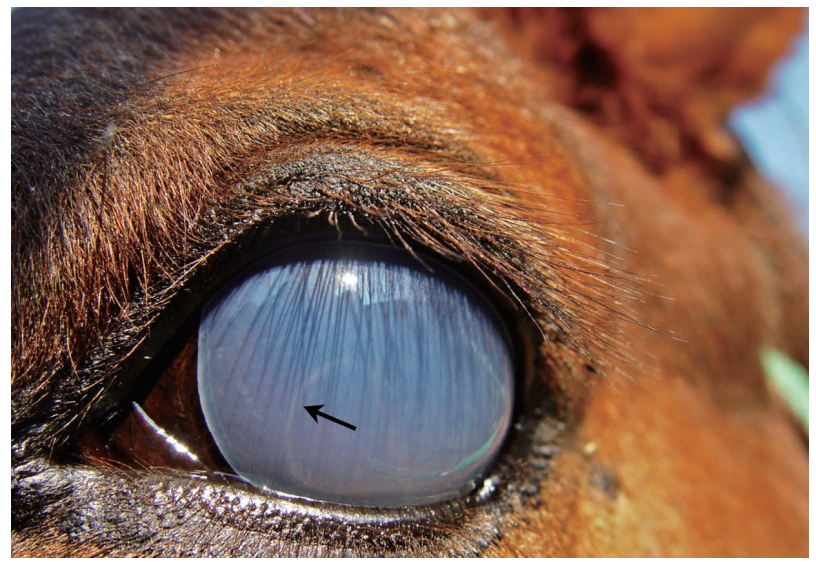

Fig. 1. A motile S. digitata (arrow) in the aqueous humor of the right eye of a Jeju pony from Miryang-si, Gyeongsangnam-do, Korea (Case 2). anterior chamber of the affected eye at 6 o'clock position of the cornea about $5 \mathrm{~mm}$ apart from the limbus. The entire parasite was successfully removed by pointing the tip of the needle near the one end of the worm and withdrawing the piston to pull the worm into the syringe.

The average length of removed worms was $3.2 \pm 0.8 \mathrm{~cm}$ in length (mean $\pm \mathrm{SD}$ ), and 7 horses were infected with the worm in the left eye and 8 on the right eye. Only 1 worm was found in the affected eye from each horse. All worms were identified as $S$. digitata by the morphologic characteristics under light and electron microscopies using the identification keys provided by Thwaite [17], Shoho et al. [18], and Rhee et al. [2]. The anterior part of the worm had dorsal and ventral projections adjacent to the round lateral lips (Figs. 2, 3). The male worm found in 4 of the cases showed a pair of lateral appendages near the posterior terminal end of the body (Fig. 4). The papillar arrangement was 3 pairs of precloacal, a pair of adcloacal, and 3 pairs of postcloacal papillae, plus a central papilla just in front of the cloaca. The female worm was characterized by a tapering posterior terminal end of the body with a smooth knob, a distinctively different feature compared to $S$. marshalli, which is bulged and roughly furcated (Fig. 5).

The cases contained herein are about ectopic parasitism of $S$. digitata in the eyes of 15 horses from Korea. Although we previously reported 2 blindness cases of cattle due to the aberrant migration of $S$. digitata into the aqueous humor [13], this is the first blindness cases of horses infected with $S$. digitata

Table 1. Summary of cases and results of worm recovery from the aqueous humor of the eye of 15 horses

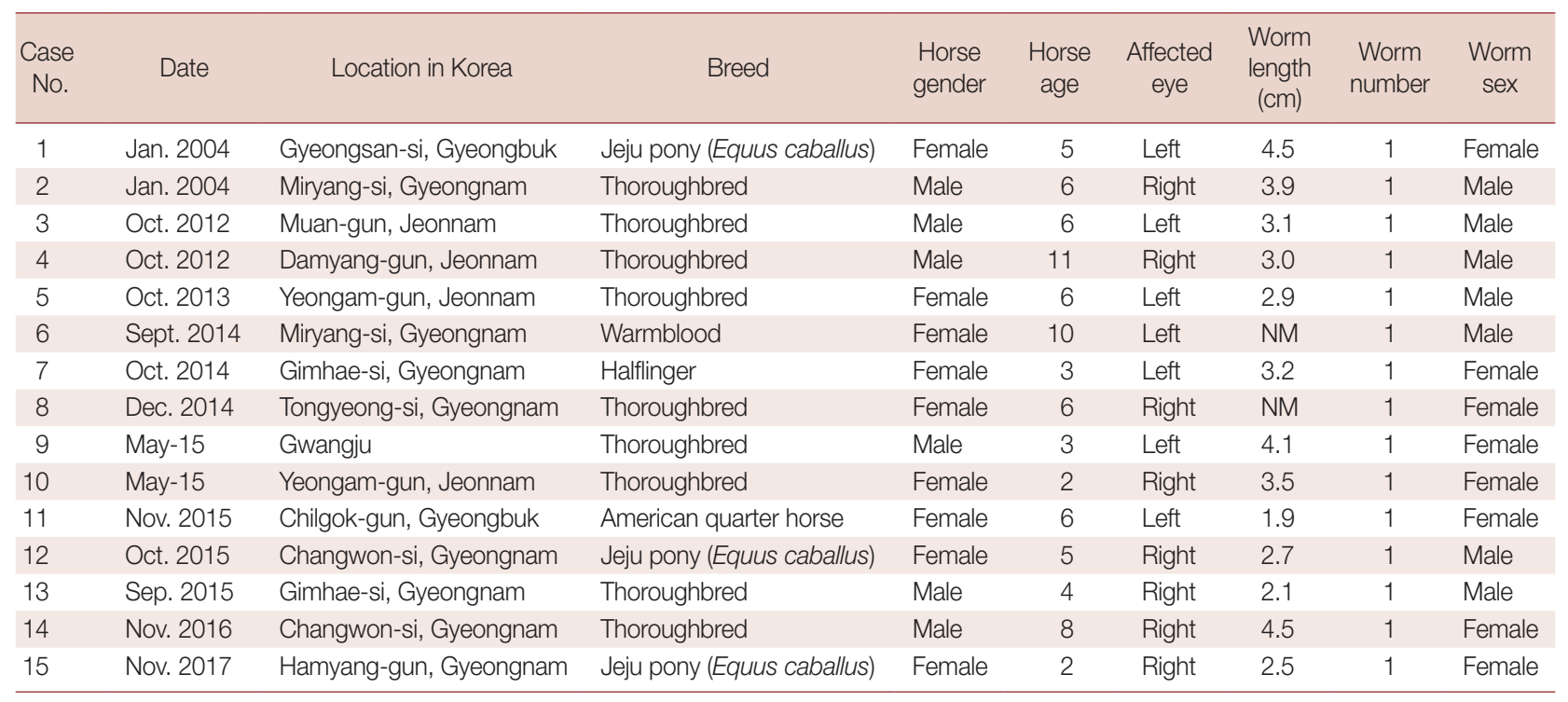

NM; not measured. 

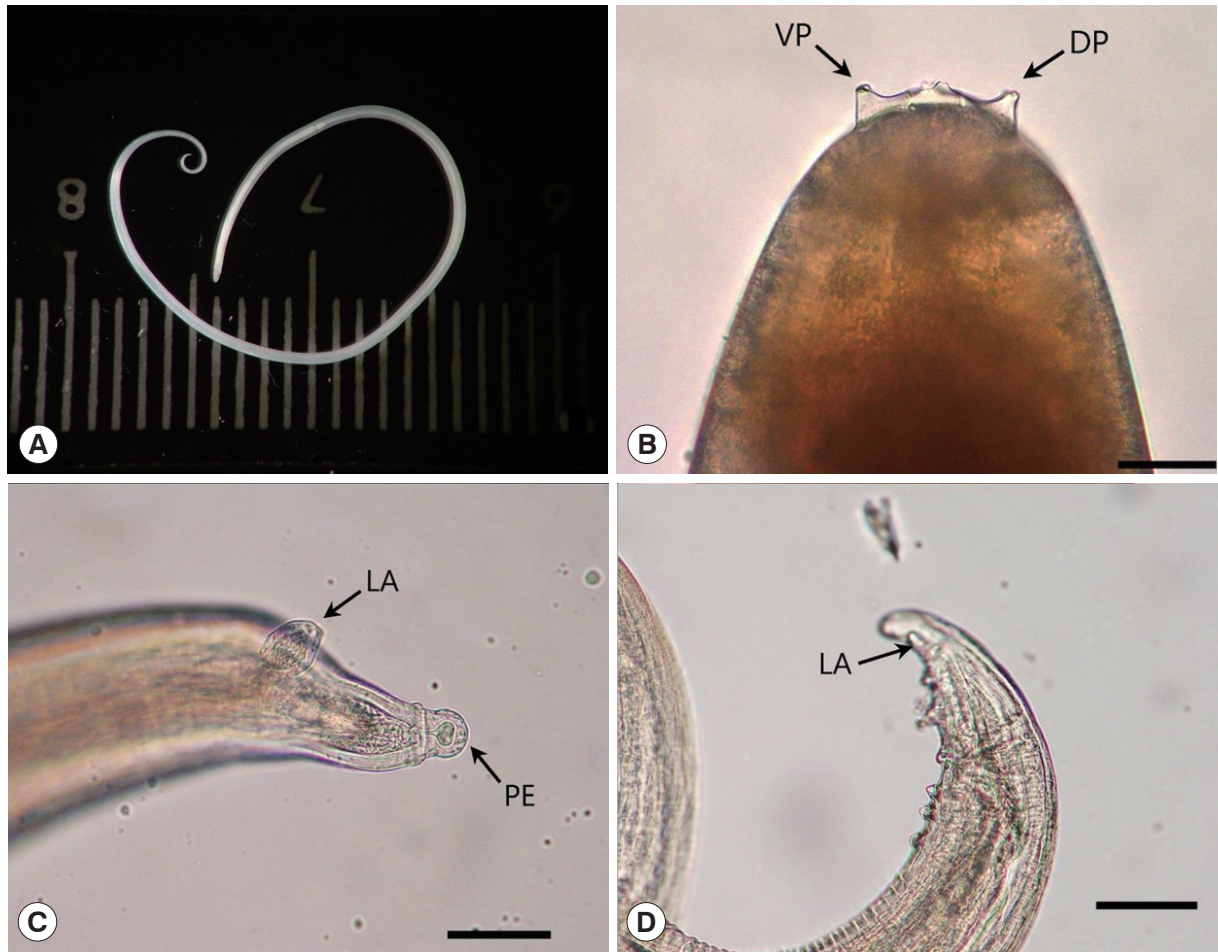

Fig. 2. Adult S. digitata removed from the anterior chamber of the eye of a horse. (A) Whole body. (B) Light microscopic view of the anterior part of the worm. (C) Posterior end of the female adult worm. (D) Posterior end of the male adult worm. ventral projection (VP), dorsal projection (DP), lateral appendage (LA), and posterior terminal end with smooth knob (PE). Scale bar =100 $\mu \mathrm{m}$.

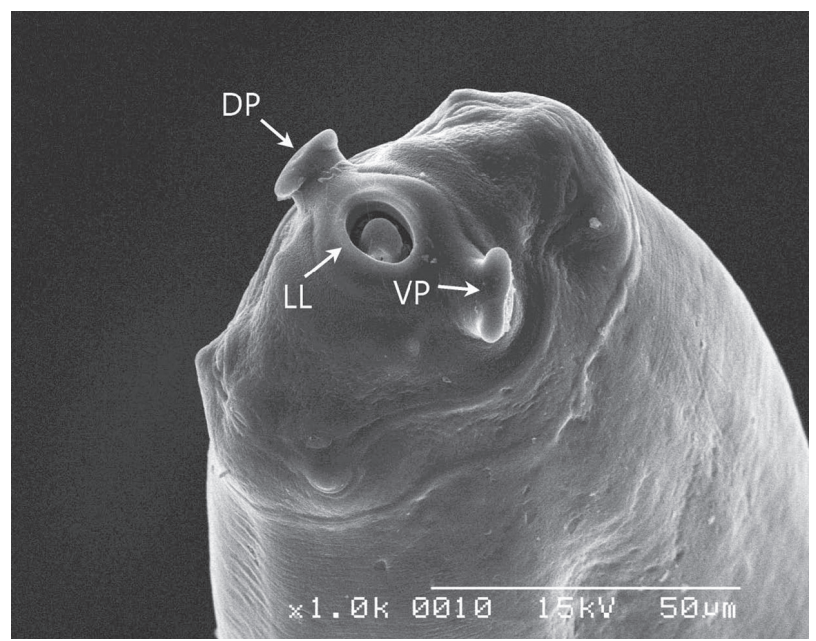

Fig. 3. Scanning electron micrograph of the anterior end of an adult male S. digitata. Dorsal projection (DP), lateral lips (LL), ventral projection (VP).

(Nematoda: Filarioidea) in Korea. For removal of worms from the eye, we followed the NPA technique designed for removing $S$. digitata from the anterior chamber of cattle, as we first reported in 2002 [13]. The NPA technique was different from the other studies in which worms were removed from the

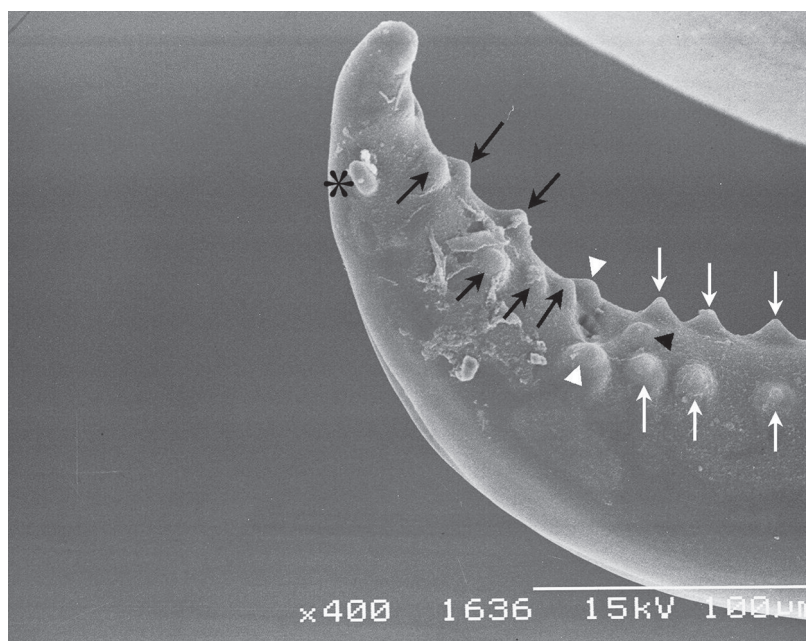

Fig. 4. Scanning electron micrograph of the posterior end of a male adult $S$. digitata. A pair of lateral appendages near the posterior terminal end of the body is present (asterisk). The papillar arrangement; 3 pairs of precloacal papillae (white arrows), a pair of adcloacal papillae (white arrow heads) and 3 pairs of postcloacal papillae (black arrows), plus a central papilla just in front of the cloaca (black arrow head).

aqueous humor by the surgical incision on the cornea $[12,19,20]$. Recent reports on the removal of ocular Setaria fol- 


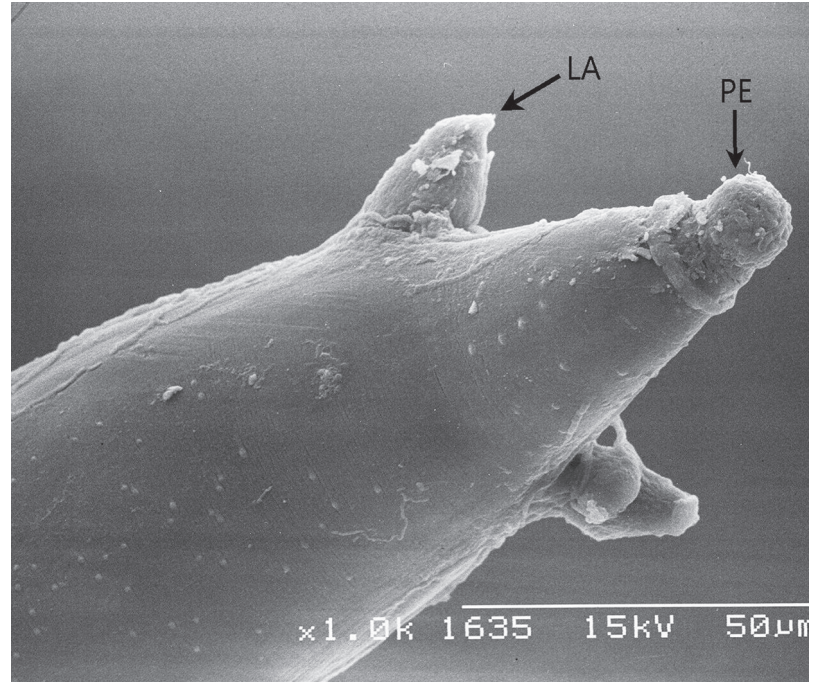

Fig. 5. Scanning electron micrograph of the posterior end of a female adult $S$. digitata. Tapering posterior terminal end of body with a smooth knob (PE) and lateral appendage ( $L A)$.

lowed our protocol, which is easier and safer than previous methods $[14,21]$. The NPA technique minimizes the damage of the vital parts of the eye and does not need to put the horse under general anesthesia. Several chemotherapeutic methods are known for treating setariasis in animals. DEC (diethylcarbamazine) $[3,16]$ or ivermectin $[22,23]$ has been generally used to treat setariasis in cattle and horses. However, chemotherapy of ocular setariasis is not recommended because the dead body of the worm that remains in the aqueous humor of the eye can exacerbate the development of opaqueness of the affected eye.

Although we presented 15 cases of equine ocular setariasis in this report, the annual incidence reported by local veterinarians ranges from 10 to 15 cases alone in Gwangju and Jeonnam areas in Korea. This implies that quite a few horses are annually infected with Setaria spp. without clinical symptoms. So far, however, the epidemiological survey of equine setariasis has not yet been available in Korea. While there have been only a few cases of equine ocular setariasis caused by $S$. equina around the world $[14,15]$, many ocular setariaisis by $S$. digitata have been reported in Asia $[4,12,15,21,24]$. The reason for the species variation of Setaria spp. in the development of ectopic parasitism is unknown, but there is a possibility that each species of Setaria elicits dissimilar immunological responses by the hosts. In the case of $S$. digitata, a non pathogenic parasite of cattle, the worm is likely to elicit stronger host immune responses in horses than in cattle. On the other hand, S. equina may cause relatively little pathogenic reaction to horses, its permissive host.

The Korean government implemented The Horse Industry Promotion Act' in 2011 in hopes of boosting rural economy. Since then the number of horse-riding facilities, parks, training schools, and academies have been rapidly increasing throughout the nation [25]. As horse riding and sports activities are increasing, however, the horse blindness by the nematode parasite in Korea should also be alerted. Our report here on the first blindness cases of horses due to $S$. digitata infection in Korea calls for a nationwide epidemiological survey of the parasite infection as well as a strategic preventive medication program against the detrimental disease in horses.

\section{ACKNOWLEDGEMENT}

We thank Dr. Choung-Seop Lee at Surabol Equine Veterinary Clinic, Gyeongju for technical support.

\section{CONFLICT OF INTEREST}

We have no conflict of interest related to this work.

\section{REFERENCES}

1. Soulsby EJL. Helminths, Arthropods and Protozoa of Domesticated Animals. Philadelphia, USA. Lea \& Febiger, 1982, pp 316319.

2. Rhee JK, Choi EY, Park BK, Jang BG. Application of scanning electron microscopy in assessing the prevalence of some Setaria species in Korean cattle. Korean J Parasitol 1994; 32: 1-6.

3. Innes J, Shoho C. Nematodes, nervous disease, and neurotropic virus infection. Br Med J 1952; 2: 366.

4. Yoshihara T, Oikawa M, Kanemaru T, Hasegawa M, Tomioka Y, Kaneko M, Uehara N, Kiryu K. Two cases of cerebrospinal setariosis in the racehorses. Bull Equine Res Inst 1987; 24: 14-22.

5. Karki K. A laboratory epidemiological outbreak investigation of Kumri (Cerebrospinal nematodiasis) and use of diethylecarbamazin in treatment of goat in Banke dis-trict of Mid-Western Region of Nepal. Vet World 2008; 1: 168-170.

6. Lee CG, Lee CY, Kwag HS. Studies on the diseases of the Korean native goat-a review. Korean J Vet Clin Med 2000; 17: 32-44.

7. Tung KC, Lai CH, Ooi HK, Yang CH, Wang JS. Cerebrospinal setariosis with Setaria marshalli and Setaria digitata infection in cattle. J Vet Med Sci 2003; 65: 977-983.

8. Yoshikawa T, Oyamada T, Yoshikawa M. Eosinophilic granulomas caused by adult setarial worms in the bovine urinary bladder. Nihon Juigaku Zasshi 1976; 38: 105. 
9. Fujita J, Imai S, Ishii T, Nunoya T, Takahashi K, Tomita T, Oikawa R. Heterotopic parasitism of Setaria digitata (Linstow, 1906) in the heart of a cattle. Nihon Juigaku Zasshi 1985; 47: 999-1002.

10. Okita N, Hanawa T, Yoshimoto M, Nakayama R. Heterotopic parasitism of Setaria digitata in the heart of eight cattle. J Japan Vet Med Assoc 1987; 40: 41-43.

11. Tamilmahan P, Zama M, Pathak R, Muneeswaran N, Karthik K. A retrospective study of ocular occurrence in domestic animals: 799 cases. Vet World 2013; 6: 274-276.

12. Jemelka E. Removal of Setaria digitata from the anterior chamber of the equine eye. Vet Med Small Anim Clin 1976; 71: 673-675.

13. Shin SS, Cho KO, Wee SH. Ocular infection of cattle with Setaria digitata. J Vet Med Sci 2002; 64: 7-10.

14. Marzok MA, Desouky AR. Ocular infection of donkeys (Equus asinus) with Setaria equina. Trop Anim Health Prod 2009; 41: 859-863.

15. Yadav A, Kumar A, Bhadwal MS, Khajuria JK, Gupta A. Ocular setariosis in horses: a case study. J Vet Parasitol 2006; 20: 183184.

16. Tamilmahan P, Zama MMS, Pathak R, Muneeswaran NS, Karthik K. A retrospective study of ocular occurences in domestic animals: 799 cases. vetworld 2013; 6: 274-276.

17. Thwaite JW. The genus Setaria. Ann Trop Med Parasitol 1927; 21:
427-466

18. Shoho C, Uni S. Scanning electron microscopy (SEM) of some Setaria species (Filarioidea, Nematoda). Z Parasitenkd 1977; 53: 93-104.

19. Ansari MM, Buchoo BA. Surgical technique for removal of intraocular parasite in horse. Intas Polivet 2005; 6.

20. Mohan K, Ananda KJ, Shridhar NB, Puttalakshmamma GC, Placid EDS. Corneal opacity due to Setaria digitata in a Jersey crossbred cow and its surgical management. vetworld 2009; 2: 69-70.

21. Jaiswal S, Singh S, Singh B, Singh H. Ocular setariosis in a horse. Intas Polivet 2006; 7: 67-68.

22. Klei TR, Torbert BJ, Ochoa R. Efficacy of ivermectin (22, 23-dihydroavermectin B 1) against adult Setaria equina and microfilariae of Onchocerca cervicalis in ponies. J Parasitol 1980; 66: 859-861.

23. Shirasaka S, Suzuki M, Endou G, Adachi Y, Taira N. Efficacy of ivermectin against Setaria microfilariae in calves and cerebrospinal setariosis in sheep and goats. J Vet Med Sci 1994; 56: 12131214.

24. Bazargani T, Eslami A, Gholami GR, Molai A, Ghafari-Charati J, Dawoodi J, Ashrafi J. Cerebrospinal nematodiasis of cattle, sheep and goats in Iran. Iran J Parasitol 2008; 3: 16-20.

25. Kim JY. The horse industry in Korea: its present condition and prospect. Adv Sci Technol Lett 2015; 99: 256-260. 
